\title{
Memória/identidade Xokó e a decolonização do ensino de História
}

\author{
Xokó memory/identity and the decolonization of teaching of History
}

\author{
Lucas Wendell de Oliveira Barreto ${ }^{1}$ \\ Valéria Maria Santana Oliveira ${ }^{2}$ \\ Ilka Miglio de Mesquita ${ }^{3}$
}

\section{Resumo}

Este texto tem por finalidade contribuir para o ensino de História indígena por lentes decoloniais que procuram tensionar as práticas educativas eurocentradas. Para tal, utilizamos como fontes de pesquisa as músicas autorais do povo Xokó, habitantes da cidade de Porto da Folha - Sergipe, reunidas e digitalizadas por meio do projeto extensionista "A aldeia vai à cidade" desenvolvido na Universidade Tiradentes, em Aracaju. Desta forma, buscamos, aqui, examinar tais músicas na intenção de compreender os sentidos de identidade Xokó e as evidências de sua trajetória. Além disso, tomamos como caminho teóricometodológico os estudos da Pedagogia Decolonial, que serviram como chave de análise das fontes e possibilitaram o vislumbre de um ensino de História que subverte as práticas educativas conhecidas como convencionais ou tradicionais e protagoniza a memória/identidade do povo indígena em questão.

Palavras-chave: Povo Xokó; História Indígena; Decolonialidade.

\begin{abstract}
This text is intended to contribute to the teaching of indigenous history through decolonial lenses that seek to tense eurocentric educational practices. To this end, we used as sources of research the copyrighted songs of the Xokó people, inhabitants of the city of Porto da Folha Sergipe, gathered and digitalized through the extension project "The village goes to the city" developed at Tiradentes University, in Aracaju. We seek here to examine such songs in order to understand the senses of Xokó identity and the evidence of their trajectory. In addition, we took as a theoretical-methodological path the studies of Pedagogy Decolonial, which served as a key analysis of sources and enabled the glimpse of a teaching of History that subverts educational practices known as conventional or traditional and protagonizes the memory/identity of the tribe in focus.
\end{abstract}

Keywords: Xokó People; Indigenous History; Decoloniality.

\section{Palavras introdutórias}

Continuamente as narrativas históricas são reescritas e, em cada época, nós, professores-pesquisadores, pesquisamos, produzimos conhecimento histórico e ensinamos a

\footnotetext{
${ }^{1}$ Licenciado em História (UNIT-SE), Mestrando em Educação (Programa de Pós-Graduação em Educação-UNIT), Membro do grupo de pesquisa História, Memória, Educação e Identidade (GPHMEI CNPQ). lucaswendelloliver@gmail.com

${ }^{2}$ Licenciada em História (UFS), Mestre em Desenvolvimento e Meio Ambiente (UFS), Especialista em Docência do Ensino Superior (UFS), Especialista em Educação Continuada e a Distância (UNB), Doutora em Educação (UNIT).profa.valeriaoliveira@gmail.com

${ }^{3}$ Licenciada em História (PUC-MG), Mestre em Educação (UFU), Doutorado em Educação (UNICAMP), Estágio pós doutoral (UFMG), Professora do PPED - UNIT, líder GPHMEI CNPQ. ilkamiglio@gmail.com
} 
partir das necessidades de nosso tempo e do olhar lançado ao passado. Assim, em tempos obscuros, é dever nosso conhecer as experiências outras vivenciadas pelos sujeitos nos interstícios da diferença cultural, e ascendê-las à sala de aula e às pesquisas. Em virtude disso, no que tange às especificidades da disciplina de História, convém observar que compõem as competências gerais da Base Nacional Comum Curricular (BNCC) a necessidade de entender e explicar a realidade através da valorização de saberes próprios das diferenças culturais que se constituem nos diversos lócus brasileiros. A proposta da BNCC, dentre outros focos, objetiva a formação do aluno para o exercício da cidadania a partir da criação de uma:

[...] capacidade de comunicação e diálogo, instrumento necessário para o respeito à pluralidade cultural, social e política, bem como para o enfrentamento de circunstâncias marcadas pela tensão e pelo conflito. A lógica da palavra, da argumentação, é aquela que permite ao sujeito enfrentar os problemas e propor soluções com vistas à superação das contradições políticas, econômicas e sociais do mundo em que vivemos. Para se pensar o ensino de História, é fundamental considerar a utilização de diferentes fontes e tipos de documento (escritos, iconográficos, materiais, imateriais) capazes de facilitar a compreensão da relação tempo e espaço e das relações sociais que os geraram. Os registros e vestígios das mais diversas naturezas (mobiliário, instrumentos de trabalho, música etc.) deixados pelos indivíduos carregam em si mesmos a experiência humana, as formas específicas de produção, consumo e circulação, tanto de objetos quanto de saberes. Nessa dimensão, o objeto histórico transforma-se em exercício, em laboratório da memória voltado para a produção de um saber próprio da história. (BRASIL, 2018, p. 398)

Fica evidenciada a importância que se dá à criticidade e ao respeito à diversidade dentro das práticas educativas, para que o cidadão esteja apto a viver em sociedade. Em consonância com esta linha de pensamento, a Constituição Federal Brasileira ${ }^{1}$, em seu artigo 3, promulgada em 1988, objetiva a promoção do bem de todos, sem preconceitos e discriminações, já o artigo 242 atribui ao ensino de História o diálogo com as diversas culturas e etnias do território brasileiro, ressaltando o respeito aos direitos humanos. Assim sendo, a construção ou (re)afirmação identitária, não por vias homogeneizantes, também compõe os objetivos de ensinar História. Neste sentido, os Parâmetros Curriculares Nacionais já destacavam em 1990 a importância da História-ensino para a formação identitária dos sujeitos. Além disso, professores-pesquisadores como Fernando Seffner e Nilton Pereira (2018), bem como Selva Guimarães Fonseca (2003), também discorrem sobe a urgência atual de trazer nas práticas educativas memórias/identidades outras, para que os alunos aprendam sobre eles mesmos e sobre outros sujeitos e suas experiências.

Partindo disto, o nosso objetivo com o presente texto é fomentar o ensino da história indígena, a partir da compreensão da trajetória dos Xokó, expressa em suas músicas autorais, 
as quais servem de recursos pedagógicos que nos munem frente às ausências de sua história, nos livros didáticos de História. Este texto também parte da necessidade de divulgarmos o acervo digital resultante das atividades de pesquisa e extensão desenvolvidas na Universidade Tiradentes - UNIT, em Aracaju, estado de Sergipe, a partir do projeto “A aldeia vai à cidade” (edital N001/2017). Este projeto consistiu em promover a preservação e divulgação da cultura indígena, através da coleta, higienização e acondicionamento de documentos existentes sobre o povo indígena Xokó, localizado na Ilha de São Pedro, na cidade de Porto da Folha, estado de Sergipe.

Este acervo comporta documentos impregnados de memória/identidade que outros pesquisadores poderão ter acesso, lançar novos olhares e evidenciar outros aspectos de suas vivências. Desta forma, o texto se divide em dois momentos: enquanto um trata do percurso que trilhamos durante a criação do acervo digital; o outro, trata especificamente dos sentidos de identidade Xokó e de sua história a partir de suas músicas autorais que podem servir de fontes nas práticas educativas.

Quanto às lentes teórico-metodológicas que guiam a nossa narrativa, optamos pela base epistemológica decolonial, desenvolvida por alguns autores da América Latina, como Vera Candau e Catherine Walsh. Este arcabouço teórico se apresenta como uma ferramenta de análise e, para além disso, uma visão de mundo, que busca a identificação e o desmantelo de estruturas de poder enraizadas desde o passado colonial (OLIVEIRA, CANDAU, 2010). Por colonialidade, entende-se como o resultado de uma geopolítica do conhecimento (ocidentalismo) que atua em função da não existência, ou existência subalternizada, de sujeitos e saberes que não se encaixam dentro de um padrão moderno/colonial, ou seja, conservador, branco, elitista, cis-gênero, heterossexual e masculinizado. O Brasil tem vivenciado ciclos de colonialidade em seus mais de quinhentos anos de existência, e isto se faz perceptível, ao analisarmos, por exemplo, a História da Educação e, sobretudo do ensino de História. Nota-se um fetichismo epistêmico ocidental, que inviabiliza uma educação democrática e representativa, sobretudo para indivíduos que historicamente foram marginalizados, como os indígenas Xokó. Assim, nossa proposta se desenvolve na contramão, como forma de romper com este pensamento colonizador e oferecer possibilidades de ensino propositivo e insurgente.

\section{Da aldeia à cidade: o trabalho de preservação da memória/identidade Xokó}


O trabalho científico/extensionista com os documentos sobre o Povo Xokó buscou promover a preservação e divulgação da cultura deste, que é o último grupo indígena do estado de Sergipe. Este objetivo foi cumprido mediante o desenvolvimento, concomitante, de três projetos. O primeiro, consistiu na pesquisa de doutoramento intitulada "Memória/Identidade Xokó: práticas educativas e reinvenção das tradições”2 ${ }^{2}$ O segundo se refere à pesquisa de Iniciação Científica (PROVIC-UNIT) intitulada “Memória Digital do Povo Indígena Xokó3”, através da qual foram pesquisados documentos de diversas tipologias. O terceiro e último, intitulado “A aldeia vai à cidade”, consistiu em uma prática extensionista desenvolvida nas modalidades de bolsa PROVEX-UNIT e PROBEX-UNIT ${ }^{4}$. Os dois últimos projetos foram desenvolvidos entre 2017 e 2018.

Todo este trabalho se justificou pela necessidade de promoção de um aspecto da história de Sergipe que sofre com a resistência dos próprios sergipanos, por não reconhecerem a identidade indígena dos Xokó. No projeto de pesquisa e extensão “A aldeia vai à cidade”, que nos proporcionou as fontes para a escrita do presente texto, foram reunidos, higienizados e digitalizados documentos sobre os indígenas, pertencentes ao Frei Enoque Salvador, missionário que atuou e ainda atua junto ao Povo Xokó. Foi realizado também o trabalho de conversão de diversas fitas VHS para o formato MP3, criação de um acervo digital no Instituto Tobias Barreto (ITBEC) ${ }^{5}$ e disponibilização dos documentos para a sociedade, nesta mesma instituição. Efetivamente, a proposta foi levar a aldeia à cidade, ou seja, se nem todas as pessoas podem se deslocar para uma terra indígena, esta passa a ir até elas, por meio dos documentos escritos e audiovisuais, coletados e preservados. A seguir, discorreremos sobre alguns aspectos importantes da trajetória percorrida na referida pesquisa.

Em 2017.2, iniciamos as atividades de higienização e digitalização dos documentos no ITBEC, com fotografias das décadas de 1970, 1980 e 1990 que registraram a trajetória do Povo Xokó. Este trabalho de preservação possibilitou a ampliação da visão a respeito da identidade indígena, bem como a aquisição de conhecimento sobre elementos que desenham a paisagem cultural do estado de Sergipe. Isso porque, aquilo que víamos não correspondia ao nosso imaginário acerca do que é ser índio e, junto com os manuscritos e o aprofundamento teórico com a pedagogia decolonial, passamos a despir o nosso olhar das armadilhas da colonialidade. Em outras palavras, aprendemos que, devido ao processo colonizador, nem sempre os povos indígenas possuem características físicas e culturais que correspondem ao estereótipo sobre eles construído em nossa sociedade. 
Avançando no trabalho com os documentos, para cada documento digitalizado foi criada uma ficha, informando a respeito do que se tratava, o estado de conservação, título, data e espaço para outros comentários. A digitalização foi feita com a utilização de um scaner e de um computador, cedidos pelo ITBEC, onde foram salvos os documentos digitalizados, em formato Joint Photographic Experts Group (JPG).

Após o armazenamento dos documentos digitais, salvaguardamos os documentos originais, categorizados nas seguintes tipologias: alocuções de Dom Brandão ${ }^{6}$, correspondências, fotografias, jornais, músicas, revistas e transcrições de gravações. Além disso, identificamos: documentos sobre a questão da posse das terras habitadas pelos Xokó: a Ilha de São Pedro; letras de músicas compostas pelos indígenas que retratam, de forma frequente, a saudade de sua terra perdida, bem como sua história de resistência; diários do Frei Enoque sobre diferentes situações que ocorreram na aldeia; cartas recebidas e documentos outros que ajudaram a compreender de forma mais efetiva, a luta travada entre os índios e os agentes da colonialidade.

Em diálogo com Quijano (2007), nos contextos (de)coloniais, o poder se refere às malhas de relações sociais caracterizadas pelo conflito de uma busca por controle dos meios de existência social (o trabalho, o sexo, a subjetividade, a natureza, a autoridade). Desta forma, partindo da empiria colonialista (sobre a qual discutiremos no próximo item) bem como de seu legado, entendemos por agentes da colonialidade aqueles indivíduos, grupos e instituições que dentro dos processos hegemônicos de poder, tentaram e tentam esmaecer as diferenças culturais em nome de um padrão moderno/colonial. No caso da trajetória dos índios Xokó, a Igreja Católica enquanto instituição, serviu de agente da colonialidade, uma vez que empreendeu seu projeto civilizatório através da cristianização de indígenas que já possuíam suas próprias tradições e religião.

Em 2018.1, as atividades consistiram na conversão das 50 fitas VHS do acervo, para o formato MP3 através do software Audacity. Após a finalização do projeto, criamos um acervo, disponibilizado no ITBEC, e organizamos uma exposição na Semana de Extensão da Unit. O "Fundo Frei Enoque" - como foi chamado o conjunto documental que organizamos, comporta hoje todos os documentos impressos que foram digitalizados, como também os arquivos de áudio e fitas VHS. A seguir, na tabela 01, apresentamos o quantitativo de documentos preservados e a tipologia:

Tabela 01: Quantitativo de documentos preservados e a tipologia 


\begin{tabular}{|c|c|c|}
\hline \multicolumn{2}{|c|}{ TIPOLOGIA DOCUMENTAL } & QUANTIDADE \\
\hline \multicolumn{2}{|c|}{ Alocuções de Dom Brandão } & 1 \\
\hline \multicolumn{2}{|c|}{ Bilhetes } & 32 \\
\hline \multicolumn{2}{|c|}{ Correspondências } & 97 \\
\hline \multicolumn{2}{|c|}{ Fotografias } & 294 \\
\hline \multirow[t]{27}{*}{ Jornais } & A defesa & 3 \\
\hline & A tarde & 6 \\
\hline & CIMI & 3 \\
\hline & COOJORNAL & 1 \\
\hline & Correio Brasiliense & 1 \\
\hline & Desacato & 1 \\
\hline & Diário de Aracaju & 3 \\
\hline & Diário de Pernambuco & 4 \\
\hline & Folha de São Paulo & 2 \\
\hline & Gazeta de Alagoas & 1 \\
\hline & Gazeta de Notícias & 2 \\
\hline & Gazeta de Sergipe & 14 \\
\hline & Jornal da Cidade & 21 \\
\hline & Jornal da Manhã & 3 \\
\hline & Jornal de Brasília & 10 \\
\hline & Jornal de Sergipe & 74 \\
\hline & Jornal do Brasil & 1 \\
\hline & Jornal Independência & 1 \\
\hline & Movimento & 1 \\
\hline & O estado de São Paulo & 22 \\
\hline & O estado de Sergipe & 2 \\
\hline & O globo & 3 \\
\hline & O São Paulo & 3 \\
\hline & Paratim & 2 \\
\hline & Porto Alegre & 1 \\
\hline & Tribuna de Alagoas & 1 \\
\hline & Tribuna de Aracaju & 9 \\
\hline
\end{tabular}




\begin{tabular}{|l|l|l|}
\hline \multirow{2}{*}{} & Última hora & 1 \\
\cline { 2 - 3 } & Vela & 1 \\
\cline { 2 - 3 } & $\begin{array}{l}\text { Matérias/documento cujo } \\
\text { jornal não foi identificado }\end{array}$ & 43 \\
\hline Músicas & 11 \\
\hline Revistas & 5 \\
\hline Transcrição das gravações & 15 \\
\hline Arquivos de áudio convertidos & 50 \\
\hline
\end{tabular}

Fonte: Acervo dos autores.

Vale ressaltar que todos estes documentos estão disponíveis em formato digital no ITBEC, situado na biblioteca da Universidade Tiradentes, campus Farolândia.

De certo, as relações hegemônicas do poder exercidas pelos agentes da colonialidade assumiram o controle dos corpos, forjaram os olhares e esmaeceram as diferenças culturais que compõem o território brasileiro. Conforme discutiremos a seguir, somente a reafirmação identitária dos Xokó, por meio da reinvenção das tradições, possibilitou sua existência em espaços sergipanos. Todavia, os resíduos históricos dos tempos coloniais se refletem, hoje, em várias instancias sociais, inclusive nas práticas educativas, assim, o trabalho de preservação de sua memória dentro do projeto extensionista em foco pode contribuir para a decolonização do olhar em relação aos modos outros de ser e estar no mundo. Neste sentido, assumimos um trabalho de orientação decolonial que, para Walsh (2009), busca desescravizar as mentes por meio de um processo de desaprendizagem. Tal processo implica o desmantelo daquilo que nos foi imposto pelas estruturas sociais enraizadas na racialização, no seio de uma educação eurocentrada que inferiorizou e inferioriza as identidades subversivas do padrão modernocolonial. Desaprender implica, também, aprender. É em virtude disso que abordaremos, por lentes decoloniais, os sentidos de identidade Xokó por meio de suas músicas, as quais enxergamos como ferramentas pedagógicas potentes para o ensino de história indígena.

\section{Os sentidos de identidade Xokó nas suas músicas e a decolonização do ensino de História}

O historiador-educador fala a partir de seu lugar social e o social não é imutável, não obstante, atravessa as diversas temporalidades incorporando as concepções que o tensionam, provocando outras questões que são lançadas ao passado, a fim de que ilumine o presente. Desta forma, os homens e as sociedades têm data de validade, os lugares sociais mudam com o tempo, 
tornando a história mutável, produzida a partir de um espaço que reflete as questões de sua realidade. Em virtude disso, o conhecimento sendo histórico se torna temporal, ou seja, muda acompanhando o percurso da história, exigindo sua reescrita sob novos métodos e olhares. José Carlos Reis (2007) afirmou que “o Brasil é conhecível pelo conjunto de interpretações feitas em épocas distintas”, desta forma, uma releitura historiográfica pode nos possibilitar uma compreensão acerca das possibilidades e urgências de ensino-pesquisa com a cultura indígena. Isso porque, dentro do panorama que o autor traça dos clássicos da historiografia brasileira, a questão da diversidade cultural do Brasil é latente. Em virtude disso, observando os saberes clássicos sistematizados por Reis (2007), a maior parte das visões clássicas da historiografia denotam uma harmonização das diferenças que não deram conta de tensionar as diversas formas de subalternização.

Diante do exposto, podemos questionar: com as tentativas de renovação teóricometodológica nas pesquisas e no ensino, avançamos em relação às histórias indígenas? A partir da leitura do texto "Ensino de História Indígena (e seus desafios) no Brasil”, do prof. Giovani da Silva, nas colunas online da Associação Brasileira do Ensino de História (ABEH) ${ }^{7}$, o autor problematiza a questão indígena e indigenista no país, ao apontar as incongruências entre o conjunto de direitos assegurados por lei e a perseguição aos povos originários no país, fomentada pelo governo, desde 2019. Partindo disso, afirma a fertilidade deste campo de investigação graças ao aumento demográfico das populações indígenas, ao avanço do movimento indígena e à aproximação entre a História e a Antropologia, que possibilita uma visão decolonial, acerca da trajetória destes povos. É importante destacar que esses avanços entram em contraste, na fala do autor, com os resíduos oitocentistas que ainda cercam a disciplina História. O exemplo citado por Silva (2019), refere-se às propostas de mudança curricular da BNCC, rechaçadas pelo Ministério da Educação no governo do presidente Michel Temer (com o apoio da Associação de Professores Universitários de História - ANPUH). Isto porque foi preconizado o aumento dos estudos indígenas e afro-brasileiros e o desmantelo do cânone europeu no ensino. Para o autor, os desafios do ensino da história indígena consistem na responsabilização dos professores de “transversalizar” os conteúdos, na liberação dos acervos de documentos impregnados de memória e na busca por atualizações teóricometodológicas acerca das questões étnico-raciais no Brasil.

É neste sentido que, no presente texto, assumimos a responsabilidade, conforme exposto anteriormente, de socializar o resultado de nossas pesquisas e atividades de extensão que envolveram a criação de um acervo digital sobre a cultura indígena Xokó. Além disso, a 
seguir, assumiremos outra responsabilidade, a de fomentar o ensino da cultura em questão, por meio de uma tipologia específica do acervo em tela, que refletem sobremaneira a trajetória do Povo Xokó: as composições musicais. Mas, como ter acesso à História, a sua memória/identidade? E quais tensões permearam e ainda permeiam esta memória/identidade? Estas são algumas questões que tentaremos pontuar aqui.

Atualmente, os Xokó residem na Ilha de São Pedro, município de Porto da Folha, sendo o único grupo indígena do estado que conseguiu resistir e existir, em meio aos ataques provenientes da colonialidade que historicamente os cercou. Embora a maior parte dos conhecimentos que temos sobre este grupo partam do século XIX, contexto que marca as ações missionárias dos Capuchinhos e outros religiosos, é necessário, nas práticas educativas da disciplina histórica, observarmos as experiencias do colonialismo/colonialidade. Este exercício/tensionamento em aula servirá para que entendamos os processos de “assujeitamento”, do controle das formas de existência para além do espectro identitário, que envolveram os indígenas e ainda reverberam em nossa sociedade. No que tange ao significado de colonialismo e colonialidade, Aníbal Quijano explica:

O controle da autoridade política, dos recursos de produção e do trabalho de uma população determinada possui uma diferente identidade e as suas sedes centrais estão, além disso, em outra jurisdição territorial. Porém nem sempre, nem necessariamente, implica relações racistas de poder. O Colonialismo é, obviamente, mais antigo; no entanto a colonialidade provou ser, nos últimos 500 anos, mais profunda e duradoura que o colonialismo. Porém, sem dúvida, foi forjada dentro deste, e mais ainda, sem ele não teria podido ser imposta à inter-subjetividade de modo tão enraizado e prolongado. (QUIJANO, 2007, p. 93)

Diante disto, é necessário que o professor-pesquisador domine os conteúdos históricos para entender o jogo do colonialismo/colonialidade que, no caso da colonização brasileira, se deu em consonância com a política do Padroado Régio. Partindo disso, em 1454, o papa Nicolau V concedeu ao infante D. Henrique o monopólio das expedições marítimas, sendo que Portugal já tinha em seu domínio as cidades de Ceuta, Arzila e outras do norte africano. Assim, podemos afirmar, com base em Georgina Santos e Ronaldo Vainfas (2014), que os portugueses eram os protetores da cristandade, desta forma, pode-se caracterizar Padroado Régio como o resultado da união entre a Igreja e o Estado, sendo estas as duas instituições basilares na efetivação do projeto civilizatório-colonizador. A igreja enfrentava alguns desafios, por exemplo, a luta entre mouros e cristãos, daí a necessidade do vínculo entre Igreja e Estado para combater esses pagãos e aumentar sua riqueza, já que a bula Romanus Pontifex dava o direito ao rei de subjugar os inimigos e tomar as terras e bens para conceder à Ordem de Jesus. 
Percebe-se que durante o Padroado Régio, o controle de autoridade foi exercido através de ferramentas de poder inseridas nas ações de aldeamentos. Segundo Maria Regina Celestino de Almeida (2014), as práticas religiosas também estavam vinculadas aos processos econômicos e políticos do regime, uma vez que havia grandes resistências, por parte das comunidades que aqui habitavam, que precisavam ser contidas. Desta forma, a construção de núcleos indígenas sob a tutela dos religiosos assegurava o bom desenvolvimento do projeto colonizador. Os colonos categorizaram os índios como “mansos” ou “selvagens”. Estes eram abatidos ou escravizados, aqueles eram submetidos aos aldeamentos que, em virtude da dificuldade de cristianização imposta pelo território brasileiro, tornou-se a opção cabível para substituir as peregrinações ${ }^{8}$. Além disso, o motivo que levou os índios a aldearem-se foi a violência das campanhas, sobretudo de Mem de Sá, nos sertões onde viviam. Sertões, aqui, não assume os significados contemporâneos, mas, diz sobre terras longínquas, de difícil acesso.

Esta contextualização é importante para que entendamos os processos históricos através dos quais foram constituídas as matrizes da colonialidade que resiste até os dias de hoje. As práticas coloniais foram perversas e isto se reflete no desaparecimento de diversos povos indígenas no Brasil, como também em Sergipe, haja vista que entre os séculos XVI e XX tínhamos os Tupinambás, Kiriri, Boimé, Kaxagó, Natu, Karapató, Aramuru, Xokó e Romari. Hoje, apenas os Xokó sobrevivem, graças a um longo processo de reinvenção das tradições (OLIVEIRA, 2018) que, em meados do século passado, pareciam ter se esvaído por completo. As ações coloniais legitimaram e ainda legitimam ações que denominamos como fruto das colonialidades. Estas, por sua vez, referem-se às ferramentas de matança, de hierarquização social dentro de relações de poder que subalternizaram e ainda subalternizam sujeitos e saberes, que excedem às normas da ordem do discurso europeizado.

A herança desse passado de colonização se faz presente no cotidiano dos Xokó. Percebemos isso na letra da canção "História dos caboclos”, de autoria de Luiz Caetano da Silva:

\section{[...]}

Era um grupo de pessoas

Que vivia escravizado

Debaixo dos pés do grande

Sem ter direito ao bocado

E pensaram em se unir

Pra poder adquirir

Seu torrão antepassado

Eu fiquei admirado 


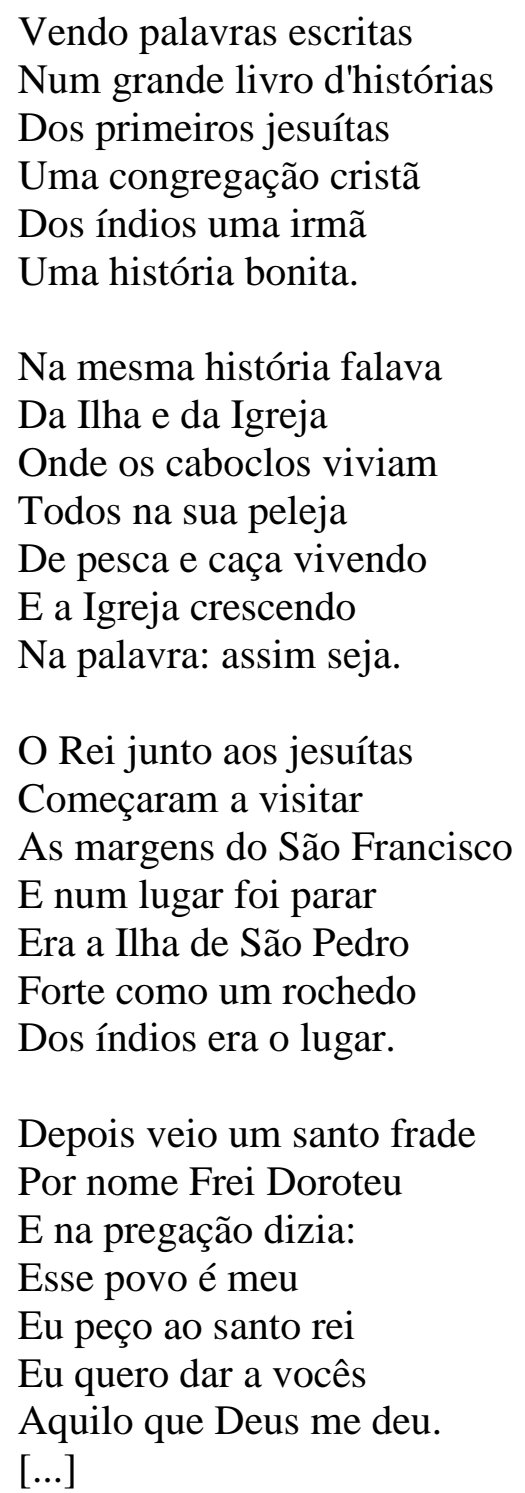

Para compreendermos e ensinarmos a história presente nesta música, precisamos desorganizar sua estrutura sequencial, interpretando-a do final ao começo. Os índios Xokó, nos processos de aldeamento, estavam sob o domínio dos padres Capuchinhos franceses desde 1672 (OLIVEIRA, MESQUITA, 2016). Por isso o sentimento de pertencimento, de controle e poder do Frei Doroteu de Loreto ${ }^{9}$ sobre os indígenas, como consta na última estrofe: "Esse povo é meu/ Eu peço ao santo rei/ Eu quero dar a vocês/ Aquilo que Deus me deu”. No diálogo com Nelson Maldonado-Torres (2008) compreendemos que a linguagem é mais que um sistema linguístico composto por palavras, é, sobretudo, ferramenta de "assujeitamento" dos corpos, uma vez que ela transmite um conhecimento que transforma um ser em um “Ser colonizado”.

Assim sendo, dentro da ordem do discurso religioso-colonial, Frei Doroteu, pertencente a um lugar hegemônico na escala societal do poder, transmitiu sua religião aos índios. Contudo, isto não significou, no curso da história, apenas a tomada do conhecimento 
dos princípios religiosos cristãos, ou um simples hibridismo cultural, mas, a perda dos principais aspectos que compunham sua identidade indígena. Isso porque, os Xokó foram proibidos de dançar o toré, uma de suas principais práticas tradicionais. Vale destacar que, ao longo da história, foram obrigados a sair dos aldeamentos para praticar suas tradições até que estas se dispersaram no passar dos anos.

O que acabamos de discutir denota uma identidade em conflito, experienciada pelo grupo em tela. Por sua vez, os versos da terceira estrofe informa-nos que aqueles aldeados já estavam imersos no processo da cristianização, o que facilitou a tutela de Frei Doroteu sobre os índios: "Na mesma história falava/ Da Ilha e da Igreja/ Onde os caboclos viviam/ Todos na sua peleja/ De pesca e caça vivendo/ E a Igreja crescendo/ Na palavra: assim seja”. Enquanto professores-pesquisadores de História, não devemos tomar este “assim seja” como reflexo de uma vida harmoniosa entre os índios e a Igreja. A relação era, pois, complexa: ora conflituosa, ora amorosa, dependendo dos interesses de cada um. Sobre isto, Oliveira e Mesquita (2016) afirmam que o Frei Doroteu despertava amor e ódio nos aldeados, isso porque, se de um lado havia a proibição das práticas culturais indígenas, por outro, somente os freis responsáveis pelas aldeias eram capazes de se aliar aos índios e lutar pelo requerimento de alguns direitos, como a propriedade das terras. Essas estratégias no trato com os grupos subjugados resultaram no sucesso do projeto civilizatório e, por conseguinte, no apego dos indígenas ao catolicismo. Além disso, os índios mais integrados ajudavam os padres na disseminação da fé cristã.

O que nos tem a dizer, portanto, as primeiras estrofes? Por que “de uma história bonita” adentramos em uma história de escravizados? E escravizados por quem? Com a morte de Frei Doroteu, os Xokó perderam o direito as suas terras e, inclusive, o direito de se autodeclararem índios. O grupo indígena se esfacelou, alguns morreram, outros se espalharam, com periódicas tentativas de retomada das terras ao longo do século XX. Eram, pois, escravos dos agentes da colonialidade, desta forma, suas tradições foram se perdendo ao longo do tempo, mas o sentimento de pertencimento às antigas terras permaneceu. Estas, só foram reentregues legalmente aos Xokó na década de 1990. Além disso, através de práticas educativas (como a escrita das próprias músicas ou criação de peças de teatro) em parceria com a Funai, antropólogos e apoio de pessoas como Frei Enoque e Dom Brandão, os indígenas conseguiram reinventar suas tradições. Desta forma, reavivou-se o sentimento de pertencimento ao passado indígena, que possibilitou a autoafirmação identitária.

Em mais uma música, desta vez de autoria de Anísio Apolônio Lima, vemos o exemplo de outra prática tradicional dos Xokó: 


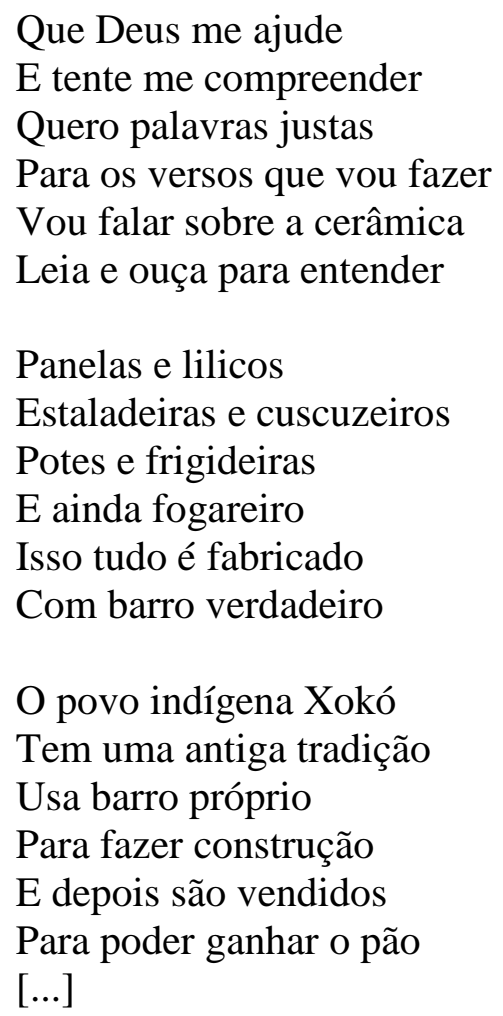

Segundo Oliveira (2018), dentro das ações cotidianas do grupo em questão, a continuidade das tradições é assegurada por práticas ritualísticas e simbólicas. Tais práticas consistem, por exemplo, na composição dos materiais provenientes do barro, como a cerâmica, que para além de ser rentável, dá sentido a identidade dos indígenas por ser uma tradição, tornando-se, assim, uma prática de resistência às técnicas coloniais de camuflagem. No que diz respeito ao processo de construção dos materiais, sobretudo da cerâmica, a autora explica que:

O primeiro passo para a confecção é a busca e o transporte da matéria-prima (barro ou argila) e do combustível (madeira para a fogueira), que são encontrados em grande quantidade na Caiçara1. A matéria-prima é escolhida pela cor e consistência, sendo necessária, no caso do barro coletado na Caiçara, a mistura de dois tipos. Somente assim se consegue a consistência adequada. Após a argila estar estocada, o próximo passo é esfarelar com uma estaca de madeira, deixando-a bem triturada para formar o xerém que é passado numa peneira chamada de urupema. A parte mais granulosa é retirada e separada, podendo posteriormente passar por um novo esfarelamento e aproveitamento. Os barros distintos e peneirados são então misturados e umedecidos aos poucos até que se obtenha a consistência adequada para o início da modelagem. A louceira retira uma porção da massa, com a qual se faz uma bola, que é colocada sobre uma espécie de prato grande, chamado de fôrma. Com os dedos, e com o auxílio de um pedaço de cabaça chamada de coité, a artesã vai esculpindo a forma desejada, utilizando também os dedos e punhos para empurrar e socar, formando assim os mais variados objetos. Em seguida, as peças 
são colocadas para secar, sendo posteriormente cozidas ou queimadas em fogueiras, transformando a argila em cerâmica. (OLIVEIRA, 2018, p. 16)

A aceitação da identidade indígena deste grupo, por parte da sociedade sergipana, continua sendo um desafio. Seus traços físicos não correspondem ao imaginário social-colonial acerca do que é ser índio. Suas habitações fogem do padrão colonial, uma vez que não vivem em ocas, bem como suas vestimentas, trabalho, forma de se portar em sociedade e religiões professadas. É interessante ressaltar, como as letras musicais bem denotam, que os Xokó são majoritariamente cristãos, mas isso não interfere no processo de identificação. Desta forma, o ensino de história indígena deve estar em conformidade com as tendências teóricas mais atuais sobre identidade, para que haja uma decolonização do pensamento social e o respeito pelos grupos étnicos brasileiros.

Tendo em vista o exposto, para Stuart Hall (1997), sequencialmente, há três primeiras perspectivas de sujeito: a do iluminismo, a sociológica e a pós-moderna. A subjetivação na ordem iluminista, que é a que por hora nos interessa, estava pautada em uma visão unificada do humano que pensava e logo existia, o centro do ser humano estava em um núcleo interior do "eu” que nascia com o indivíduo e se desenvolvia com ele, independente do contato com o social que o cercava. Desta forma, tínhamos uma perspectiva de sujeito essencialmente individualista, autossuficiente e imutável. É esta perspectiva, própria dos auspícios da ciência moderna cujas bases foram lançadas pelo colonialismo/colonialidade, que influencia ainda o imaginário acerca dos processos identitários. Sobre isto, Homi Bhabha (2013, p. 117) explica que:

Um aspecto importante do discurso colonial é sua dependência do conceito de "fixidez" na construção ideológica da alteridade. A fixidez, como signo da diferença cultural/histórica/racial no discurso do colonialismo, é um modo de representação paradoxal: conota rigidez e ordem imutável como também desordem, degeneração e repetição demoníaca. Do mesmo modo, o estereótipo, que é sua principal estratégia discursiva, é uma forma de conhecimento e identificação que vacila entre o que está sempre "no lugar", já conhecido, e algo que deve ser ansiosamente repetido... como se a duplicidade essencial do asiático ou a bestial liberdade sexual do africano, que não precisam de prova, não pudessem na verdade ser provados jamais no discurso.

O legado colonial que marca as lentes culturais através das quais enxergamos o mundo é resultado, na perspectiva de Bhabha, desta construção colonial de um sujeito fixo. O lugar do sujeito que foi historicamente estabelecido é de indolência, selvageria e primitividade. Todavia, em contraposição a esta perspectiva de sujeito, encontra-se em Bhabha e em Hall um sujeito dinâmico que, diferente daquele fixo, é formado na relação com a coletividade na qual está 
inserido e não possui uma identidade una, mas, formada por várias posições de sujeito que estão em constante conflito. Assim, desloca-se do lugar identitário pré-estabelecido na ordem colonial do discurso, e passa a habitar nas margens da colonialidade, nos interstícios indentitários. As relações de poder presentes na sociedade em que o indivíduo habita, dão sentido a sua forma de ser e estar no mundo. No entanto, isso não significa que este sujeito seja passivo frente aos processos históricos de assujeitamentos, pelo contrário, a mudança de um sujeito fixo para um sujeito dinâmico é fundamental para entendermos que existem possibilidades de agência do ser humano assujeitado ao longo da história. Ou seja, de ressignificação identitária pelos próprios sujeitos, uma vez que onde há poder, há resistência. Observemos, pois, a letra da seguinte música:

Graças a Deus, a festa começou

A ilha de São Pedro os caboclos já ganhou

No dia 7, quando o bispo anunciou

Lá na igreja Matriz que os caboclos ganhou

Foi tanta alegria que muita gente chorou

A força da irmandade na união

Por isso você que é pobre se una com seu irmão (bis)

Dom José Brandão de Castro, o bispo de Propriá

Se somou com Frei Enoque que só vive a trabalhar

Pelos pobres que não têm terra e casa pra morar

A igreja e o sindicato

E o povo trabalhador

Se uniram aos caboclos

Nesta luta de valor (bis)

Como podemos entender o sujeito-outro dos entre-lugares da identidade nesta música composta pelo Xokó Zé Bezerra? Destacam-se dois elementos que, se a identidade fosse fixa e imutável, não viria a ocorrer. O primeiro a observar consiste na autodenominação, pelos Xokó, de "caboclo", nome dado aos índios que perdiam as guerras de batalha e que em tempos imperiais, o próprio grupo étnico rejeitava. O segundo, refere-se à religiosidade católica, uma vez que, na perspectiva de sujeito fixo, o indígena precisa cultuar suas divindades de origem. É essencial que nas aulas de história indígena coloquemos em destaque que os processos identitários são mutáveis. Esta comunidade indígena, por sua vez, acompanhou o ritmo da sociedade em que estava inserida, os traços de seu corpo que refletem uma miscigenação histórica, sua forma de ser e estar em um mundo globalizado não são fatores que negam sua 
identidade. Mas, o que a atesta é seu modo de identificação social a partir de símbolos culturais e sentimento de pertença a um grupo que historicamente sofreu com as ferramentas da colonialidade, mas que hoje resiste para continuar existindo. Daí a importância de trabalharmos sua história em sala de aula.

\section{Palavras finais}

É evidente que precisamos ensinar uma história indígena, portanto, este texto para além de abordar esta necessidade, proporcionou recursos para sua efetivação. Nesta narrativa, assumimos o compromisso que nos foi dado pelo professor Giovani da Silva de encarar os desafios do ensino da história indígena, que consistem na transversalização do conteúdo, na socialização dos acervos de documentos sobre indígenas e na busca por lentes teóricometodológicas que sejam capazes de abordar as relações étnico-raciais no Brasil por um olhar “outro”. Assim sendo, se de um lado trouxemos à público os resultados das nossas práticas científico-extensionistas que buscaram preservar o acervo pessoal do Frei Enoque sobre os Xokó; de outro, a partir de uma visão decolonial e em íntima relação com estudos sobre identidade, tecemos comentários sobre a trajetória dos indígenas, tendo como suporte e como recurso pedagógico as letras de suas músicas.

Reconhecer e respeitar nas aulas as questões que levantamos é não negar o olhar a uma trajetória de hibridismos culturais, bem como tensionar as experiências humanas nas fronteiras da diferença cultural. O legado do colonialismo está presente nas diversas instancias sociais, inclusive nas práticas educativas que podem nos servir como ferramentas de transformação de uma mentalidade rudimentar que ainda mantém a cultura indígena, não somente a sergipana, fora dos currículos. Isso porque, este legado foi construído no seio de um repúdio das diferenças culturais legitimando práticas homogeneizantes e predatórias. Assim, se em tempos coloniais tais práticas consistiam na cristianização e civilização de indígenas, hoje, em tempos de colonialidade, a identidade Xokó é negada uma vez que há ainda uma dificuldade social em aceitar que os processos identitários são mutáveis.

Desta forma, é necessário que o professor-pesquisador busque em diversos recursos, suportes que supram a ausência de certas temáticas nos livros didáticos. Trabalhamos, aqui, com uma etnicidade que ainda não é bem explorada nos materiais didáticos, logo, as músicas, as correspondências, as imagens, os jornais e outros documentos do nosso acervo se tornam possibilidades de uma história pública a ser trabalhada em sala de aula. Ademais, a responsabilidade do professor no ensino desta história indígena é romper com uma 
epistemologia eurocêntrica que impossibilita o desenvolvimento de práticas políticas de currículo com saberes outros. De fato não há possibilidade de decolonizar o ensino se ainda lançarmos um olhar do colonizador para as experiências vividas.

É neste sentido que uma educação intercultural se faz necessária, para que o ensino se torne reflexo das efervescências de movimentos sociais por visibilidade e reparação histórica, partindo, das relações de poder e sua manutenção de um racismo estrutural. O compromisso ético com as identidades, que desenham a nossa paisagem social na contemporaneidade, tornase urgente na prática docente. A ruptura com a perspectiva do sujeito fixo para uma noção de individuo, formado a partir do meio em que está inserido, serviu de chave de análise para entendermos as identidades em contextos (de)coloniais e que somos, sim, frutos de vozes que nos antecedem, como ficou evidente na construção identitária Xokó problematizada por nós, a partir das músicas. Isto reflete uma capacidade de agência, de mobilização de sujeitos que possibilita um processo de contestação social, de resistência, de quebra de valores e normas que invisibilizaram sujeitos que precisam protagonizar as aulas de História.

\section{Referências bibliográficas}

ALMEIDA, Maria Regina Celestino de. Catequese, aldeamento e missionação. In: FRAGOSO, João; GOUVÊA, Maria de Fátima (Org.). O Brasil colonial volume 1. Rio de Janeiro: Civilização Brasileira, 2014, p. 435-472.

BHABHA, Homi K. O local da cultura. Tradução Myriam Ávila, Eliana Lourenço de Lima Reis, Gláucia Renate Gonçalves. Belo Horizonte: Editora UFMG, 2013.

BRASIL. Ministério da Educação. Base nacional comum curricular. Brasília, DF: MEC, 2018. Disponível em: http://basenacionalcomum.mec.gov.br/images/BNCC_EI_EF_110518_versaofinal_site.p df; acesso em: 01 ago. 2019.

BRASIL. Constituição Federal de 1988. Promulgada em 5 de outubro de 1988. Disponível em http://www.planalto.gov.br/ccivil_03/constituicao/constituição.htm; acesso em: 01 ago. 2019.

FONSECA, Selva Guimarães. Didática e prática do ensino de história: experiências, reflexões e aprendizado. Campinas: Papirus, 2003.

HALL, S. Identidades Culturais na Pós-Modernidade. Tradução Tomaz Tadeu da Silva, Guacira Lopes Louro. Rio de Janeiro: DP\&A, 1997.

MALDONADO-TORRES, Nelson. A Topologia do Ser e a Geopolítica do Conhecimento: modernidade, império e colonialidade. In: SANTOS, Boaventura de Sousa; MENESES, Maria Paula (Org.). Epistemologias do Sul. Coimbra: Almedina, 2009, p. 337-382.

OLIVEIRA, Luiz Fernandes de; CANDAU, Vera Maria Ferrão. Pedagogia decolonial e educação antirracista e intercultural no Brasil. Belo Horizonte: Educ. rev. v.26, n.01, p. 15-40, 2010.

OLIVEIRA, Valéria Maria Santana. Memória/identidade Xokó: práticas educativas e reinvenção das tradições. Tese (Doutorado em Educação) - Programa de Pós-graduação em Educação da Universidade Tiradentes. Aracaju: UNIT, 2018. 
OLIVEIRA, Valéria Maria Santana; MESQUITA, Ilka Miglio de. Povo Xokó: reinvenção das tradições. In: LUCENA, Simone; LUCINI, Marizete (Org.). Educação, comunicação e diversidade: pesquisa e conexões. Rio de Janeiro: Autografia, 2016.

QUIJANO, Aníbal. Colonialidade do poder e classificação social. In: SANTOS, Boaventura de Sousa; MENESES, Maria Paula (Org.). Epistemologias do Sul. Coimbra: Almedina, 2009, p. 73-118.

REIS, José Carlos. As identidades do Brasil: de Varnhagen a FHC. Rio de Janeiro: FGV, 2007.

SANTOS, Georgina; VAINFAS, Ronaldo. Igreja, inquisição e religiosidades coloniais. In: FRAGOSO, João; GOUVÊA, Maria de Fátima (Org.). O Brasil colonial volume 1. Rio de Janeiro: Civilização Brasileira, 2014, p. 479-517.

SEFFNER, F.; PEREIRA, Nilson M. Ensino de História: passados vivos e educação em questões sensíveis. Revista História Hoje: v. 7, n 13, p. 14-33, 2018.

SILVA, Giovani. Ensino de História Indígena (e seus desafios) no Brasil. Disponível em: https://hhmagazine.com.br/o-desafio-da-historia-indigena-e-de-seu-ensino-no-brasil/; acesso em: 02 ago. 2019.

WALSH, Catherine. Interculturalidade crítica e pedagogia decolonial: in-surgir, re-existir e re-viver. In. CANDAU, Vera Maria (Org.). Educação intercultural na América Latina: entre concepções, tensões e propostas. Rio de Janeiro: 7 Letras, 2009. p. 12-42.

\footnotetext{
${ }^{1}$ BRASIL. Constituição Federal de 1988. Promulgada em 5 de outubro de 1988. Disponível em http://www.planalto.gov.br/ccivil_03/constituicao/constituição.htm. Acesso em: 01 ago. 2019.

${ }^{2}$ Pesquisa de doutoramento desenvolvida por Valéria Maria Santana Oliveira, entre 2015 e 2018, orientada pela Prof ${ }^{\mathrm{a}} \mathrm{Dr}^{\mathrm{a}}$ Ilka Miglio de Mesquita.

${ }^{3}$ Pesquisa desenvolvida pela bolsista Rafaela Matos de Santana Cruz, então aluna do curso de História da Universidade Tiradentes, orientada pela Prof ${ }^{a} \operatorname{Dr}^{a}$ Ilka Miglio de Mesquita.

${ }^{4} \mathrm{O}$ projeto de extensão teve como bolsista PROVEX-UNIT Lucas Wendell de Oliveira Barreto e como bolsista PROBEX-UNIT, Ítalo Jonathan Custódio dos Santos, orientados pela orientada pela $\operatorname{Prof}^{\mathrm{a}} \mathrm{Dr}^{\mathrm{a}}$ Valéria Maria Santana Oliveira.

${ }^{5}$ O Instituto Tobias Barreto de pesquisa e cultura é um órgão da Universidade Tiradentes, voltado para a preservação da cultura e história de Sergipe.

${ }^{6}$ Dom José Brandão de Castro foi um bispo da Igreja Católica que, assim como frei Enoque, prestou assistência religiosa ao Povo Xokó.

7 SILVA, Giovani. Ensino de História Indígena (e seus desafios) no Brasil. Disponível em: https://hhmagazine.com.br/o-desafio-da-historia-indigena-e-de-seu-ensino-no-brasil/; acesso em: 02 ago. 2019.

${ }^{8} \mathrm{O}$ processo de cristianização até então ocorria por meio de peregrinações. Nestas, os religiosos assumiam a missão de ir até os incrédulos para pregar os princípios cristãos. Os aldeamentos subverteram esta prática, uma vez que fixaram em determinados espaços os locais de convertimento.

${ }^{9}$ Último missionário que atuou junto aos Xokó.
} 